\title{
The Zymovars of Vibrio cholerae: Multilocus Enzyme Electrophoresis of Vibrio cholerae
}

\author{
Fernanda S Freitas, Hooman Momen, Carlos Andre Salles
}

Laboratório de Sistemática Bioquímica, Departamento de Bioquímica e Biologia Molecular, Instituto Oswaldo Cruz-Fiocruz, Av. Brasil 4365, 21045-900 Rio de Janeiro, RJ, Brasil

Zymovars analysis also known as multilocus enzyme electrophoresis is applied here to investigate the genetic variation of Vibrio cholerae strains and characterise strains or group of strains of medical and epidemiological interest.

Fourteen loci were analyzed in 171 strains of non-O1 non-O139, 32 classical and 61 El Tor from America, Africa, Europe and Asia. The mean genetic diversity was 0.339 .

It is shown that the same $O$ antigen (both $O 1$ and non-O1) may be present in several geneticaly diverse (different zymovars) strains. Conversely the same zymovar may contain more than one serogroup.

It is confirmed that the South American epidemic strain differs from the 7th pandemic El Tor strain in locus LAP (leucyl leucyl aminopeptidase). Here it is shown that this rare allele is present in $1 \mathrm{~V}$. mimicus and 4 non-O1 V. cholerae.

Non toxigenic O1 strains from South India epidemic share zymovar 14A with the epidemic El Tor from the 7th pandemic, while another group have diverse zymovars.

The sucrose negative epidemic strains isolated in French Guiana and Brazil have the same zymovar of the current American epidemic V. cholerae.

Key words: Vibrio cholerae - enzyme electrophoresis - genetic diversity

The electrophoretic mobility of enzymes has been used to detect allelic variation of the respective genes in several microorganisms including Vibrio cholerae (Salles \& Momen 1991, Chen et al. 1991, Wachsmuth et al. 1993, Beltran et al. 1999).

In our previous papers we focused on the problem of finding a reliable genetic distinction between the biotypes classical and El Tor and to evaluate the degree of genetic variation prevalent among this species.

Then we defined a zymovar as the set of strains having the same electromorphs among the loci investigated and zymovar analysis the procedures required to determine it. This approach is also known as Multi-Locus Enzyme Electrophoresis and zymovar as electrophoretic type, or ET.

The study of $V$. cholerae using molecular tools introduced considerable change in our views affecting the bacteriology and the epidemiology of cholera. Here we present results obtained with 14 loci from a large sample of strains.

\section{MATERIALS AND METHODS}

Geographical origin of strains - Algeria, Australia, Burma, Bangladesh, Brazil, Bolivia, Colombia, Chile, Czech Republic, China, Sri Lanka, France, Ghana, Guatemala, Guiana, Hong Kong, India, Indonesia, Israel, Italy, Japan, Kuwait, Malaysia, Marroc, Mexico, Nepal, Nigeria, Paki-

This project received financial support from Faperj.

${ }^{+}$Corresponding author. Fax: +55-21-2598.3495. E-mails: csalles@gene.dbbm.fiocruz.br; caqps@ig.com.br

Received 18 July 2001

Accepted 25 February 2002 stan, Peru, Philippines, Russia, Rwanda, Singapore, Tanzania, Thailand, Turkey, UK, USA, Venezuela, Zimbabwe.

Sources of strains - B Davies, Peggy Pereira, P Desmarchelier, R Colwell, Glenn Morris Jr, GB Nair, AC Ghose, B Said, JV Lee, NICED (India), JM Fournier, L Amenuvor, and our own collection.

Most of the general bacteriological, electrophoretical and computational procedures have been described previously (Salles \& Momen 1991).

The enzyme loci mentioned in the tables and text have been described previously (Salles \& Momen 1991). They are: ACO (aconitase hydratase); ADH (alanine dehydrogenase); IDH (isocitrate dehydrogenase); ME (malic enzyme); NSE (carboxilesterase); PGD (6-phosphogluconate dehydrogenase); MDH (malate dehydrogenase); PGM (phosphoglucomutase); GPI (glucose phosphate isomerase); G6P (glucose-6-phosphatedehydrogenase) ; PD (proline dipeptidase); P1 (peptidase leucyl-leucyl-leucine); P2 (peptidase leucyl glycil glycine) with the addition of the locus LAP: leucyl leucyl aminopeptidase (Pasteur et al. 1990).

Genetic diversity was estimated according to Selander et al. (1986). The genetic diversity per locus GDL is calculated from allele frequencies as

$$
\mathrm{GDL}=1-\left[\Sigma \mathrm{Ai}^{2}(\mathrm{n} / \mathrm{n}-1)\right]
$$

were $\mathrm{Ai}$ is the frequency of the ith allele in locus $\mathrm{A}$ and $\mathrm{n}$ the number of zymovars. The expression $n / n-1$ is a correction for small samples. Mean genetic diversity MGD is the arithmetic average of GDL over all loci.

\section{RESULTS}

Table I shows the electromorphs of 134 zymovars obtained from 155 strains of $V$. cholerae non O1 non O139 plus the zymovars of El Tor 7th pandemic (14A), ElTor S. American pandemic (14B) and classical (13). For the 
TABLE I

Alleles present in each zymovar of Vibrio cholerae

\begin{tabular}{|c|c|c|c|c|c|c|c|c|c|c|c|c|c|c|}
\hline$\overline{\mathrm{ZYMO}}$ & $\mathrm{ACO}$ & $\mathrm{ADH}$ & IDH & $\mathrm{ME}$ & NSE & PGD & $\mathrm{MDH}$ & PGM & GPI & G6P & PD & $\mathrm{P} 1$ & P2 & LAP \\
\hline N 001 & 1 & 1 & 1 & 2 & 2 & 3 & 4 & 2 & 3 & 3 & 4 & 3 & 3 & 2 \\
\hline N 002 & 1 & 1 & 1 & 2 & 5 & 3 & 4 & 2 & 3 & 3 & 4 & 3 & 1 & 2 \\
\hline N 003 & 1 & 1 & 1 & 2 & 5 & 3 & 4 & 2 & 3 & 2 & 5 & 3 & 1 & 2 \\
\hline N 004 & 1 & 1 & 1 & 2 & 5 & 3 & 3 & 2 & 3 & 5 & 4 & 2 & 1 & 2 \\
\hline N 005 & 1 & 1 & 1 & 2 & 5 & 3 & 3 & 2 & 3 & 1 & 3 & 2 & 1 & 1 \\
\hline N 006 & 1 & 1 & 1 & 2 & 5 & 3 & 3 & 2 & 3 & 4 & 4 & 2 & 1 & 2 \\
\hline 2007 & 1 & 1 & 1 & 2 & 5 & 3 & 3 & 1 & 3 & 4 & 2 & 2 & 1 & 2 \\
\hline N 008 & 1 & 1 & 2 & 2 & 5 & 3 & 3 & 2 & 3 & 4 & 3 & 2 & 1 & 2 \\
\hline N 009 & 1 & 1 & 1 & 2 & 5 & 6 & 3 & 0 & 3 & 4 & 5 & 2 & 1 & 1 \\
\hline 2010 & 1 & 1 & 1 & 2 & 5 & 5 & 3 & 1 & 3 & 4 & 5 & 2 & 1 & 2 \\
\hline 2011 & 1 & 1 & 1 & 2 & 5 & 4 & 3 & 2 & 3 & 2 & 5 & 2 & 1 & 2 \\
\hline 2012 & 1 & 1 & 1 & 2 & 5 & 4 & 3 & 2 & 2 & 2 & 5 & 2 & 1 & 2 \\
\hline 1013 & 1 & 1 & 1 & 2 & 4 & 2 & 3 & 2 & 3 & 5 & 4 & 2 & 1 & 2 \\
\hline N 015 & 1 & 1 & 1 & 2 & 5 & 3 & 3 & 2 & 3 & 3 & 1 & 1 & 1 & 2 \\
\hline 2016 & 1 & 1 & 1 & 2 & 5 & 1 & 3 & 2 & 3 & 6 & 2 & 2 & 1 & 2 \\
\hline 2017 & 1 & 1 & 1 & 2 & 5 & 5 & 4 & 1 & 3 & 5 & 3 & 2 & 1 & 2 \\
\hline 2018 & 1 & 1 & 1 & 2 & 6 & 3 & 1 & 2 & 1 & 4 & 4 & 2 & 1 & 1 \\
\hline $\mathrm{N} 022$ & 1 & 1 & 1 & 2 & 3 & 3 & 3 & 2 & 3 & 4 & 5 & 2 & 1 & 1 \\
\hline N 023 & 1 & 1 & 1 & 2 & 5 & 4 & 3 & 2 & 3 & 4 & 4 & 2 & 1 & 2 \\
\hline N 024 & 1 & 1 & 1 & 2 & 4 & 1 & 3 & 2 & 3 & 5 & 4 & 2 & 1 & 2 \\
\hline 2025 & 1 & 1 & 1 & 2 & 5 & 3 & 3 & 2 & 3 & 2 & 5 & 2 & 1 & 2 \\
\hline 2026 & 1 & 1 & 1 & 2 & 5 & 3 & 3 & 2 & 2 & 2 & 6 & 2 & 1 & 2 \\
\hline 2027 & 1 & 1 & 1 & 2 & 4 & 3 & 4 & 2 & 3 & 4 & 4 & 3 & 1 & 2 \\
\hline 2028 & 1 & 1 & 1 & 2 & 5 & 3 & 4 & 2 & 3 & 2 & 5 & 2 & 1 & 2 \\
\hline N 029 & 1 & 1 & 1 & 2 & 4 & 3 & 3 & 3 & 2 & 4 & 3 & 2 & 1 & 2 \\
\hline N 030 & 1 & 1 & 1 & 2 & 5 & 3 & 4 & 2 & 3 & 4 & 4 & 2 & 1 & 2 \\
\hline N 031 & 1 & 2 & 1 & 2 & 5 & 3 & 3 & 2 & 3 & 4 & 5 & 2 & 1 & 2 \\
\hline N 032 & 1 & 1 & 1 & 2 & 5 & 4 & 3 & 0 & 3 & 5 & 4 & 3 & 1 & 2 \\
\hline N 033 & 1 & 1 & 1 & 2 & 4 & 3 & 3 & 1 & 3 & 4 & 4 & 3 & 1 & 1 \\
\hline N 035 & 1 & 1 & 1 & 2 & 5 & 3 & 3 & 2 & 4 & 4 & 4 & 3 & 3 & 1 \\
\hline N 036 & 1 & 1 & 1 & 2 & 5 & 3 & 3 & 2 & 2 & 5 & 4 & 2 & 2 & 2 \\
\hline N 037 & 1 & 1 & 1 & 2 & 5 & 3 & 3 & 2 & 2 & 5 & 2 & 3 & 1 & 1 \\
\hline N 038 & 1 & 1 & 1 & 2 & 4 & 3 & 3 & 2 & 3 & 5 & 4 & 2 & 1 & 2 \\
\hline N 039 & 1 & 1 & 1 & 2 & 5 & 3 & 3 & 2 & 3 & 5 & 4 & 2 & 1 & 1 \\
\hline N 041 & 1 & 1 & 1 & 2 & 5 & 4 & 4 & 2 & 3 & 5 & 4 & 2 & 1 & 2 \\
\hline N 042 & 1 & 1 & 1 & 3 & 5 & 3 & 4 & 2 & 3 & 5 & 3 & 3 & 1 & 1 \\
\hline N 043 & 1 & 1 & 0.5 & 2 & 5 & 4 & 3 & 2 & 3 & 4 & 1 & 3 & 1 & 2 \\
\hline N 045 & 2 & 1 & 1 & 2 & 5 & 3 & 3 & 2 & 3 & 5 & 3 & 2 & 1 & 1 \\
\hline N 046 & 1 & 1 & 1 & 2 & 0 & 3 & 3 & 2 & 3 & 4 & 4 & 3 & 1 & 1 \\
\hline N 047 & 1 & 1 & 1 & 2 & 5 & 3 & 4 & 2 & 3 & 5 & 3 & 3 & 1 & 2 \\
\hline N 048 & 1 & 1 & 1 & 2 & 5 & 3 & 4 & 2 & 3 & 5 & 4 & 2 & 1 & 2 \\
\hline N 049 & 1 & 1 & 1 & 2 & 5 & 3 & 4 & 2 & 3 & 5 & 5 & 2 & 1 & 2 \\
\hline N 050 & 1 & 1 & 1 & 2 & 5 & 3 & 4 & 2 & 3 & 5 & 6 & 3 & 1 & 2 \\
\hline N 051 & 1 & 1 & 1 & 2 & 5 & 3 & 4 & 2 & 3 & 5 & 5 & 3 & 1 & 2 \\
\hline N 052 & 1 & 1 & 1 & 2 & 5 & 3 & 4 & 1 & 3 & 5 & 4 & 2 & 1 & 2 \\
\hline N 053 & 1 & 1 & 1 & 2 & 5 & 3 & 3 & 2 & 3 & 5 & 4 & 3 & 0 & 1 \\
\hline 2054 & 1 & 1 & 1.5 & 2 & 5 & 4 & 3 & 1 & 3 & 5 & 5 & 2 & 1 & 2 \\
\hline N 055 & 1 & 1 & 1 & 2 & 5 & 3 & 3 & 2 & 3 & 5 & 5 & 2 & 1 & 2 \\
\hline N 056 & 1 & 1 & 1 & 2 & 5 & 3 & 3 & 2 & 3 & 4 & 4 & 3 & 1 & 2 \\
\hline N 057 & 1 & 1 & 1 & 2 & 5 & 3 & 3 & 2 & 3 & 4 & 3 & 3 & 1 & 1 \\
\hline N 058 & 1 & 1 & 1 & 2 & 5 & 3 & 3 & 2 & 3 & 4 & 5 & 3 & 1 & 2 \\
\hline N 059 & 1 & 1 & 1 & 2 & 5 & 3 & 3 & 2 & 3 & 4 & 2 & 3 & 1 & 0 \\
\hline N 060 & 1 & 1 & 1 & 2 & 5 & 4 & 3 & 2 & 3 & 4 & 6 & 2 & 1 & 3 \\
\hline N 061 & 1 & 1 & 1 & 2 & 5 & 5 & 3 & 2 & 3 & 4 & 5 & 0 & 0 & 2 \\
\hline N 062 & 1 & 1 & 1 & 2 & 5 & 3 & 4 & 2 & 3 & 4 & 3 & 2 & 1 & 2 \\
\hline N 063 & 1 & 1 & 1 & 2 & 5 & 3 & 4 & 2 & 3 & 4 & 2 & 2 & 1 & 1 \\
\hline N 064 & 1 & 1 & 1 & 2 & 5 & 3 & 4 & 2 & 3 & 5 & 4 & 4 & 1 & 2 \\
\hline N 065 & 1 & 1 & 1 & 2 & 5 & 3 & 4 & 2 & 3 & 4 & 4 & 3 & 1 & 2 \\
\hline N 066 & 1 & 1 & 1 & 2 & 5 & 5 & 3 & 2 & 3 & 4 & 4 & 2 & 1 & 2 \\
\hline N 067 & 1 & 1 & 1 & 2 & 5 & 4 & 4 & 2 & 2 & 4 & 4 & 2 & 2 & 0 \\
\hline N 068 & 1 & 1 & 1 & 2 & 5 & 5 & 3 & 2 & 3 & 4 & 4 & 3 & 1 & 0 \\
\hline N 069 & 1 & 1 & 1 & 2 & 5 & 5 & 3 & 2 & 3 & 4 & 5 & 3 & 2 & 2 \\
\hline
\end{tabular}




\begin{tabular}{|c|c|c|c|c|c|c|c|c|c|c|c|c|c|c|}
\hline ZYMO & $\mathrm{ACO}$ & ADH & IDH & $\mathrm{ME}$ & NSE & PGD & $\mathrm{MDH}$ & PGM & GPI & G6P & PD & $\mathrm{P} 1$ & P2 & LAP \\
\hline $\mathrm{N} 070$ & 1 & 1 & 1 & 2 & 5 & 3 & 3 & 2 & 2 & 4 & 6 & 3 & 2 & 3 \\
\hline 2071 & 1 & 1 & 1 & 2 & 5 & 3 & 3 & 2 & 2 & 5 & 4 & 2 & 1 & 2 \\
\hline N 072 & 0.5 & 1 & 1 & 2 & 5 & 1 & 3 & 2 & 3 & 5 & 4 & 2 & 1 & 2 \\
\hline N 073 & 1 & 1 & 1 & 2 & 5 & 3 & 4 & 2 & 3 & 4 & 4 & 3 & 2 & 2 \\
\hline N 074 & 1 & 1 & 1 & 2 & 5 & 5 & 3 & 2 & 3 & 4 & 5 & 3 & 1 & 2 \\
\hline N 075 & 1 & 1 & 1 & 2 & 5 & 5 & 3 & 2 & 3 & 4 & 5 & 3 & 1 & 1 \\
\hline N 076 & 1 & 2 & 1 & 2 & 5 & 3 & 4 & 2 & 3 & 4 & 4 & 3 & 1 & 2 \\
\hline N 077 & 1 & 1 & 1 & 2 & 6 & 4 & 3 & 2 & 3 & 3 & 4 & 2 & 1 & 2 \\
\hline N 078 & 1 & 3 & 3 & 2 & 6 & 2 & 3 & 2 & 3 & 3 & 3 & 1 & 1 & 3 \\
\hline N 079 & 1 & 3 & 3 & 2 & 6 & 2 & 4 & 2 & 3 & 4 & 5 & 2 & 1 & 0 \\
\hline N 080 & 1 & 1 & 1 & 2 & 5 & 5 & 3 & 2 & 3 & 4 & 5 & 3 & 1 & 2 \\
\hline N 080 & 1 & 1 & 1 & 2 & 5 & 5 & 3 & 2 & 3 & 4 & 5 & 3 & 1 & 2 \\
\hline N 081 & 1 & 1 & 1 & 2 & 5 & 3 & 3 & 0 & 4 & 2 & 3 & 3 & 1 & 2 \\
\hline N 082 & 1 & 1 & 1 & 2 & 5 & 3 & 3 & 2 & 3 & 4 & 3 & 2 & 1 & 2 \\
\hline N 083 & 1 & 1 & 1 & 2 & 5 & 3 & 3 & 2 & 2 & 4 & 3 & 2 & 1 & 1 \\
\hline N 084 & 1 & 1 & 1 & 2 & 5 & 3 & 4 & 2 & 3 & 3 & 4 & 1 & 1 & 1 \\
\hline N 085 & 1 & 1 & 1 & 2 & 5 & 3 & 4 & 1 & 3 & 4 & 4 & 3 & 1 & 1 \\
\hline N 086 & 1 & 1 & 1 & 2 & 5 & 2 & 3 & 2 & 3 & 4 & 2 & 3 & 1 & 2 \\
\hline N 087 & 1 & 1 & 1 & 2 & 5 & 3 & 4 & 2 & 2 & 4 & 4 & 3 & 1 & 2 \\
\hline N 088 & 1 & 1 & 1 & 2 & 5 & 3 & 3 & 2 & 2 & 4 & 3 & 4 & 1 & 2 \\
\hline N 089 & 1 & 1 & 1 & 2 & 5 & 4 & 4 & 2 & 3 & 4 & 5 & 2 & 1 & 2 \\
\hline N 090 & 1 & 1 & 1 & 2 & 5 & 3 & 3 & 1 & 3 & 5 & 5 & 2 & 1 & 0 \\
\hline N 091 & 1 & 1 & 1 & 2 & 5 & 3 & 4 & 2 & 3 & 4 & 3 & 3 & 2 & 2 \\
\hline N 092 & 1 & 1 & 1 & 2 & 5 & 3 & 4 & 2 & 3 & 4 & 3 & 2 & 1 & 2 \\
\hline N 093 & 1 & 1 & 1 & 2 & 5 & 3 & 4 & 2 & 3 & 4 & 3 & 3 & 1 & 2 \\
\hline N 094 & 1 & 1 & 1.5 & 2 & 5 & 3 & 4 & 1 & 2 & 5 & 5 & 1 & 1 & 2 \\
\hline N 095 & 1 & 1 & 1 & 2 & 5 & 3 & 4 & 3 & 3 & 4 & 3 & 2 & 1 & 1 \\
\hline N 096 & 1 & 1 & 1 & 2 & 5 & 3 & 4 & 2 & 3 & 4 & 5 & 3 & 1 & 2 \\
\hline N 098 & 1 & 1 & 1 & 2 & 5 & 3 & 3 & 2 & 4 & 4 & 4 & 3 & 1 & 2 \\
\hline N 099 & 1 & 1 & 1 & 2 & 5 & 3 & 3 & 2 & 3 & 5 & 3 & 2 & 1 & 2 \\
\hline N 100 & 1 & 1 & 1 & 2 & 5 & 2 & 3 & 1 & 3 & 5 & 4 & 2 & 1 & 0 \\
\hline N 101 & 1 & 1 & 1 & 2 & 5 & 3 & 4 & 1 & 3 & 5 & 6 & 2 & 1 & 2 \\
\hline N 102 & 1 & 1 & 1 & 2 & 5 & 3 & 4 & 1 & 3 & 5 & 4 & 3 & 1 & 2 \\
\hline N 103 & 1 & 1 & 1 & 2 & 5 & 3 & 3 & 2 & 2 & 4 & 4 & 3 & 1 & 2 \\
\hline N 104 & 1 & 1 & 1 & 2 & 5 & 3 & 3 & 2 & 3 & 5 & 4 & 1 & 1 & 2 \\
\hline N 105 & 1 & 1 & 1 & 2 & 5 & 3 & 3 & 2 & 3 & 5 & 2 & 2 & 1 & 2 \\
\hline N 106 & 1 & 1 & 1 & 2 & 5 & 2 & 3 & 1 & 3 & 5 & 4 & 2 & 1 & 2 \\
\hline N 107 & 1 & 1 & 1 & 2 & 5 & 3 & 3 & 2 & 3 & 5 & 4 & 3 & 1 & 2 \\
\hline N 108 & 1 & 2 & 1 & 2 & 5 & 4 & 3 & 2 & 3 & 5 & 5 & 2 & 1 & 2 \\
\hline N 109 & 1 & 1 & 1 & 2 & 5 & 4 & 3 & 1 & 3 & 3 & 5 & 2 & 1 & 2 \\
\hline N 110 & 1 & 1 & 1 & 2 & 5 & 3 & 3 & 3 & 3 & 5 & 3 & 2 & 1 & 2 \\
\hline N 111 & 1 & 1 & 1 & 2 & 5 & 3 & 3 & 1 & 2 & 4 & 4 & 2 & 1 & 1 \\
\hline N 112 & 1 & 1 & 1 & 2 & 5 & 4 & 3 & 2 & 3 & 4 & 4 & 2 & 1 & 1 \\
\hline N 113 & 1 & 1 & 1 & 2 & 4 & 3 & 3 & 2 & 3 & 4 & 4 & 2 & 1 & 2 \\
\hline N 114 & 1 & 1 & 1 & 2 & 5 & 3 & 3 & 1 & 3 & 4 & 4 & 3 & 1 & 1 \\
\hline N 116 & 1 & 1 & 1 & 2 & 5 & 3 & 4 & 1 & 2 & 4 & 4 & 4 & 1 & 2 \\
\hline N 117 & 0.5 & 1 & 1 & 2 & 5 & 4 & 3 & 1 & 2 & 4 & 5 & 1 & 1 & 2 \\
\hline N 118 & 1 & 1 & 2 & 1 & 5 & 3 & 3 & 2 & 3 & 5 & 3 & 2 & 2 & 1 \\
\hline N 119 & 1 & 1 & 1 & 2 & 5 & 3 & 4 & 2 & 3 & 4 & 4 & 2 & 1 & 1 \\
\hline N 120 & 1 & 1 & 1 & 2 & 5 & 3 & 4 & 2 & 2 & 5 & 4 & 3 & 1 & 2 \\
\hline N 121 & 1 & 1 & 1 & 2 & 5 & 3 & 4 & 2 & 3 & 5 & 4 & 3 & 1 & 0 \\
\hline N 122 & 1 & 1 & 1 & 2 & 5 & 3 & 4 & 2 & 2 & 4 & 4 & 2 & 1 & 2 \\
\hline N 123 & 1 & 1 & 1 & 2 & 5 & 3 & 3 & 1 & 3 & 5 & 4 & 2 & 1 & 1 \\
\hline N 124 & 1 & 1 & 1 & 2 & 5 & 4 & 4 & 1 & 2 & 5 & 5 & 2 & 1 & 2 \\
\hline N 141 & 1 & 1 & 1 & 2 & 5 & 2 & 3 & 1 & 3 & 4 & 5 & 1 & 2 & 2 \\
\hline N 142 & 1 & 1 & 1 & 2 & 5 & 4 & 4 & 2 & 3 & 4 & 5 & 2 & 2 & 2 \\
\hline N 143 & 1 & 1 & 1 & 2 & 5 & 2 & 4 & 2 & 3 & 4 & 2 & 1 & 2 & 2 \\
\hline N 144 & 0.5 & 1 & 1 & 2 & 5 & 3 & 4 & 2 & 3 & 4 & 4 & 3 & 2 & 2 \\
\hline N 145 & 2 & 1 & 1 & 2 & 5 & 4 & 3 & 2 & 3 & 4 & 5 & 2 & 2 & 2 \\
\hline N 146 & 1 & 1 & 1 & 2 & 5 & 4 & 3 & 2 & 3 & 4 & 4 & 2 & 2 & 2 \\
\hline N 147 & 1 & 1 & 1 & 2 & 5 & 2 & 3 & 3 & 3 & 4 & 4 & 2 & 2 & 2 \\
\hline $114 \mathrm{~A}$ & 1 & 1 & 1 & 2 & 4 & 3 & 3 & 2 & 2 & 5 & 4 & 2 & 1 & 1 \\
\hline $1 \mathrm{14B}$ & 1 & 1 & 1 & 2 & 4 & 3 & 3 & 2 & 2 & 5 & 4 & 2 & 1 & 3 \\
\hline 2152 & 1 & 1 & 1 & 2 & 5 & 4 & 3 & 2 & 4 & 2 & 5 & 2 & 1 & 5 \\
\hline N 153 & 1 & 1 & 1 & 2 & 5 & 3 & 3 & 2 & 3 & 5 & 2 & 2 & 1 & 1 \\
\hline
\end{tabular}




\begin{tabular}{|c|c|c|c|c|c|c|c|c|c|c|c|c|c|c|}
\hline ZYMO & $\mathrm{ACO}$ & $\mathrm{ADH}$ & IDH & $\mathrm{ME}$ & NSE & PGD & $\mathrm{MDH}$ & PGM & GPI & G6P & PD & $\mathrm{P} 1$ & $\mathrm{P} 2$ & LAP \\
\hline N 154 & 2 & 1 & 1 & 2 & 5 & 3 & 3 & 2 & 3 & 5 & 3 & 2 & 1 & 2 \\
\hline N 155 & 1 & 1 & 1 & 2 & 5 & 4 & 3 & 1 & 3 & 4 & 3 & 3 & 1 & 3 \\
\hline N 156 & 1 & 1 & 1.5 & 2 & 5 & 3 & 3 & 1 & 3 & 4 & 5 & 3 & 1 & 1 \\
\hline N 157 & 1 & 1 & 1.5 & 2 & 5 & 4 & 3 & 1 & 3 & 4 & 3 & 2 & 1 & 2 \\
\hline N 158 & 1 & 1 & 1 & 2 & 5 & 3 & 3 & 1 & 3 & 4 & 4 & 2 & 1 & 2 \\
\hline N 159 & 1 & 1 & 1 & 2 & 5 & 4 & 4 & 1 & 3 & 4 & 5 & 3 & 1 & 2 \\
\hline N 160 & 1 & 1 & 1 & 2 & 5 & 4 & 3 & 2 & 2 & 4 & 4 & 2 & 1 & 2 \\
\hline N 161 & 1 & 1 & 1 & 2 & 5 & 3 & 4 & 1 & 2 & 4 & 4 & 2 & 1 & 2 \\
\hline N 162 & 1 & 1 & 1.5 & 2 & 5 & 3 & 4 & 2 & 2 & 5 & 4 & 1 & 2 & 2 \\
\hline N 163 & 1 & 1 & 1 & 2 & 5 & 3 & 3 & 2 & 2 & 4 & 4 & 2 & 1 & 2 \\
\hline N 164 & 1 & 1 & 1 & 2 & 5 & 3 & 3 & 2 & 3 & 4 & 5 & 3 & 2 & 2 \\
\hline N 165 & 1 & 1 & 1 & 2 & 5 & 3 & 3 & 2 & 3 & 4 & 3 & 3 & 1 & 2 \\
\hline
\end{tabular}

N: non O1 non O139 zymovars; 1: O1 and O139 epidemic strains: zymovar 14A El Tor 7th pandemic Old World, zymovar14B El Tor American pandemic and zymovar 13 classical strains; 2: O1 strains non zymovar 13 or 14; ZYMO: zymovar; ACO (aconitase hydratase); ADH (alanine dehydrogenase); IDH (isocitrate dehydrogenase); ME (malic enzyme); NSE (carboxilesterase); PGD (6phosphogluconate dehydrogenase); MDH (malate dehydrogenase); PGM (phosphoglucomutase); GPI (glucose phosphate isomerase); G6P (glucose-6-phosphatedehydrogenase) ; PD (proline dipeptidase); P1 (peptidase leucyl-leucyl-leucine); P2 (peptidase leucyl glycil glycine) with the addition of the locus LAP: leucyl leucyl aminopeptidase (Pasteur et al. 1990).

present purpose the O139 strains (Bengal) are equated with El Tor 7th Pandemic with the same zymovar 14A.

The genetic diversity per locus was as following: ACO0.092 ADH-0.064 IDH-0.133 ME-0.003 NSE-0.222 PGD0.525 MDH-0.453 PGM-0.392 GPI-0.334 G6P-0.588 PD0.690 P1-0.553 P2-0.314 LAP-0.461.

The mean genetic diversity (MGD) was 0.339 , $\mathrm{sd}=0.2$.

Table III list selected O1 serogroup strains isolated from clinical and environmental sources with zymovars other than 13 or 14 showing the correspondence or lack of it between zymovar, serogroup, CT, TCP and sources.

\section{DISCUSSION}

The present estimate of MGD is 0.339 . Our previous estimated MGD was 0.326 using nearly half the strains of the present study. Chen et al. (1991) found 0.311 and
Beltran et al. (1999) from a large sample of American non$\mathrm{O} 1$ isolates found a higher diversity of 0.436 .

A possible source of variation in MGD seems to be the choice of loci. Our choice was aimed at finding loci diagnostic of the species $V$. cholerae with low genetic diversity GD and this may have biased in part the MGD. This diversity is considerable and is of the same level of Escherichia coli but still less than some Gram negative bacteria.

We have been unable to find significant correlation between zymovars and pathogenic/epidemic potential except, partially, in the case of the zymovars 13,14 A and $14 \mathrm{~B}$ (O1-O139 epidemic strains). It is however interesting to note that the allele NSE 4 present in zymovars 13 and 14 is not frequent (10/136) among non-O1 non-O139 and other O1 isolates. NSE 4 group include some strains of the most frequent serogroups of non-O1 V. cholerae iso-

TABLE II

Profiles for 14 loci in 138 zymovars

\begin{tabular}{|c|c|c|c|c|c|c|c|c|c|}
\hline \multicolumn{10}{|c|}{ Alleles } \\
\hline Loci & 0 & 0.5 & 1 & 1.5 & 2 & 3 & 4 & 5 & 6 \\
\hline $\mathrm{ACO}$ & 1 & 3 & 131 & 0 & 3 & 0 & 0 & 0 & 0 \\
\hline $\mathrm{ADH}$ & 0 & 0 & 133 & 0 & 3 & 2 & 0 & 0 & 0 \\
\hline IDH & 0 & 1 & 128 & 5 & 2 & 2 & 0 & 0 & 0 \\
\hline $\mathrm{ME}$ & 0 & 0 & 1 & 0 & 136 & 1 & 0 & 0 & 0 \\
\hline NSE & 0 & 0 & 0 & 0 & 1 & 1 & 10 & 122 & 0 \\
\hline PGD & 0 & 0 & 3 & 0 & 9 & 91 & 25 & 9 & 1 \\
\hline $\mathrm{MDH}$ & 0 & 0 & 1 & 0 & 0 & 91 & 46 & 0 & 0 \\
\hline PGM & 3 & 0 & 27 & 0 & 104 & 4 & 0 & 0 & 0 \\
\hline GPI & 0 & 0 & 1 & 0 & 24 & 109 & 4 & 0 & 0 \\
\hline G6P & 0 & 0 & 1 & 0 & 8 & 7 & 76 & 45 & 1 \\
\hline PD & 0 & 0 & 2 & 0 & 9 & 25 & 62 & 35 & 5 \\
\hline $\mathrm{P} 1$ & 1 & 0 & 8 & 0 & 78 & 48 & 3 & 0 & 0 \\
\hline $\mathrm{P} 2$ & 2 & 0 & 119 & 0 & 15 & 2 & 0 & 0 & 0 \\
\hline LAP & 7 & 0 & 27 & 0 & 98 & 5 & 0 & 1 & 0 \\
\hline
\end{tabular}

ACO (aconitase hydratase); ADH (alanine dehydrogenase); IDH (isocitrate dehydrogenase); ME (malic enzyme); NSE (carboxilesterase); PGD (6-phosphogluconate dehydrogenase); MDH (malate dehydrogenase); PGM (phosphoglucomutase); GPI (glucose phosphate isomerase); G6P (glucose-6-phosphatedehydrogenase); PD (proline dipeptidase); P1 (peptidase leucyl-leucyl-leucine); P2 (peptidase leucyl glycil glycine) with the addition of the locus LAP: leucyl leucyl aminopeptidase (Pasteur et al. 1990). 
lated from human sources, O37 and O5 (Donovan 1984). This locus seems to be useful for a preliminary screening of new strains.

Most genes investigated are housekeeping genes necessarily conserved for the survival of the organism. The know pathogenicity islands are phages or phage-like mobile elements responsible for the lateral transfer of non essential genes coding cholera toxin (CT) and toxin coregulated pilli (TCP) (Karaolis et al. 1999, Faruque et al. 1999) and genes coding somatic $\mathrm{O}$ antigens as in the Bengal O139. This latter strain is genetically an El Tor 7th pandemic zymovar $14 \mathrm{~A}$ which received from a non-O1 vibrio, genes coding a modified LPS (Johnson et al. 1994, Bik et al. 1995). It is therefore unlikely that strong correlation may be found between zymovars and antigenic or virulence factors carried by these mobile elements.

The strain responsible for the American pandemic is not the same strain causing the 7th pandemic. As show by Wachsmuth et al. (1993) and our results, it differ in locus LAP, with allele 3 while the Old World pandemic strains have allele 1 . The 7th pandemic in the Old World is caused by zymovar $14 \mathrm{~A}$ and the American pandemic by zymovar 14B. Both pandemics are usually described as the same 7th pandemic but the genetic distinction between the two agents may suggest an independent origin of the later. This poses an interesting epidemiological problem, the origin of the American pandemic, the agent and source of the first cases of cholera in Peru. LAP 3 is not common in our sample and may be equally rare among
V. cholerae in nature. Locus LAP has epidemiological interest since cholera on the Atlantic coast may be due to the prevalent clone but may be the result of import from the Old World.

A novelty brought by the American pandemic was the detection of epidemic V. cholerae O1 zymovar 14B sucrose negative. It was first isolated in French Guiana (JM Fournier, pers. commun.) and later spread to Brazilian Amazon region (De Paula et al. 1997). The production of acid from sucrose in cholera diagnostic medium TCBS is a characteristic of most $V$. cholerae used for the initial isolation and identification procedures. Although many sucrose negative strains have been described by Desmarchelier and Reichelt (1984), none were O1 and epidemic. This may be the first occurrence of epidemic O1 with such phenotypic variation.

Table III list few strains of O1 serogroup with diverse genetic profiles. Strains from South India and Amazon Brazil have been studied in detail by Saha et al. (1996) and Coelho et al. (1995) respectively. The India strains with the same zymovar of the epidemic strain (14A) seems to be derived from the later with loss of the CT cluster but conserved TCP. The Amazon strains belong to a diverse genetic group (zymovar 54) and do not have CT and TCP. Therefore CT, TCP and the O1 antigen may not be linked to any particular zymovar.

An interesting consequence of the fact that the $\mathrm{O} 1$ antigen does not define a clone and is found in many genetically diverse strains is that past epidemiological

TABLE III

Vibrio cholerae serogroup $\mathrm{O} 1$ with diverse zymovars

\begin{tabular}{lllllll}
\hline NO & ZYMO & CT & TCP & Source & Location & Place \\
\hline 041 & 007 & - & - & Water & USA & Guam \\
224 & 007 & - & - & Water & USA & Cpeak Bay \\
261 & 007 & - & - & Water & Australia & Ashmore RF \\
325 & 007 & - & - & Fish & Australia & Santos, SP \\
009 & 010 & - & - & Water & Brazil & Georges R \\
182 & 011 & - & - & Water & Australia & Georges RV \\
279 & 011 & - & - & Water & Australia & Blaye \\
492 & 011 & - & - & Human & France & Kent \\
038 & 012 & - & - & Water & UK & N.Pine Dam \\
89 & 016 & - & - & Water & Australia & N.Pine Dam \\
247 & 016 & - & - & Water & Australia & Condamine \\
266 & 016 & - & - & Water & Australia & N.S.Wales \\
273 & 016 & - & - & Water & Australia & Georges R \\
314 & 016 & - & - & Water & Australia & Brisbane \\
180 & 018 & - & - & Animal & Australia & Georges RV \\
181 & 018 & - & - & Water & Australia & Rockhampto \\
183 & 018 & - & - & Water & Australia & Beenleigh \\
309 & 018 & - & - & Water & Australia & Bulumba R \\
259 & 025 & - & + & Water & Australia & Georges RV \\
236 & 026 & - & - & Water & Australia & Amazonia \\
239 & 027 & - & + & Water & Brazil & Florida \\
293 & 028 & - & - & Water & USA & Louisiana \\
370 & 054 & - & - & Human & Australia & Clarence R \\
360 & 071 & - & - & Human & Water &
\end{tabular}

NO: our strain no.; ZYMO: zymovar; CT: CTx cholera toxin gene; TCP: toxin co-regulated pili 
accounts of cholera outbreaks and epidemics (Pollitzer 1960, Wachsmuth et al. 1994) must be reviewed with caution when the isolation of $\mathrm{O} 1$ organisms from the environment is connected to clinical cases.

Attempts to type strains of $V$. cholerae have been made involving detection of differences in the Vibrio's genome (RAPD, ribotyping etc). The RAPD applied to protozoa gave results in agreement with multilocus data (Tibayrenc et al. 1993) and may be a promising tool while the shortcomings with ribotyping (Lan \& Reeves 1998) and the possibility of intense lateral gene transfer between organisms (Doolittle 1999) including V. cholerae (Cruz \& Davies 2000) renders the interpretation of rybotyping and similar techniques rather problematic. A combination of multilocus enzyme electrophoresis with DNA sequencing of the loci studied proposed by Maiden et al. (1998) may show promising results.

\section{ACKNOWLEDGEMENTS}

To the scientists mentioned in Materials and Methods section for providing strains, their serogroup and clinical-epidemiological information. To Ana Carolina Vicente and Veronica Vieira (Genetic Department, IOC) for data on Cholera Toxin gene and Toxin Co-regulated Pili gene of several strains and helpful advice.

\section{REFERENCES}

Beltran P, Delgado G, Navarro A, Trujillo F, Selander RK, Cravioto A 1999. Genetic diversity and population structure of Vibrio cholerae. J Clin Microbiol 37: 581-590.

Bik EM, Bunschoten AE, Gouw RD, Mooi FR 1995.Genesis of the novel epidemic Vibrio cholerae O139 strain: evidence for horizontal transfer of genes involved in polysaccharide synthesis. EMBO J 14: 209-216.

Coelho A, Andrade JRC, Vicente ACP, Salles CA 1995. New variant of Vibrio cholerae $\mathrm{O} 1$ from clinical isolates in Amazonia. J Clin Microbiol 33: 114-118.

Chen F, Evins GM, Cook WL, Almeida R, Hargreett -Bean N, Wachsmuth K 1991. Genetic diversity among toxigenic and non-toxigenic Vibrio cholerae O1 isolated from the western hemisphere. Epidemiol Infect 1: 225-233.

Cruz F, Davies J 2000. Horizontal gene transfer and the origin of species: lessons from bacteria. Trends Microb 8: 128133.

De Paula RFL, Lins-Laison ZC, Da Silva EL, Proietti Jr AA, Mareco ML, Lamarao ML 1997. Cholera in north Brazil: on the occurrence of strains of Vibrio cholerae $\mathrm{O} 1$ which fail to ferment sucrose during routine plating on thiosulphate-citrate-bile salt-sucrose agar (TCBS). A new problem in diagnosis and control ? Ver Latinoam Microbiol 39: 141-144.

Donovan T 1984. Serology and serotyping of Vibrio cholerae. In RRColwell, The Vibrios, John Willey \& Sons, New York, p. 83-101.

Doolittle WF 1999. Phylogenetic classification and the universal tree. Science 284: 2124-2128.

Desmarchelier P, Reichelt JL 1984. A phenotypic and genetic study of sucrose nonfermenting strains of Vibrio mimicus and Vibrio cholerae. Curr Microbiol 10: 41-48.

Faruque MS, Rahman MM, Asaldugh, Islam NMK, Mekalanos JJ 1999. Lysogenic conversion of environmental Vibrio mimicus strains by CTX J Infec Immun 67: 5723-5729.

Johnson JA, Salles CA, Panigrahi P, Albert JM, Wright AC, Johnson RJ, Morris GJ Jr 1994. Vibrio cholerae O139 synonym Bengal is closely related to Vibrio cholerae El Tor but has important differences. Infect Immun 62: 2108-2110.

Karaolis DKR, Somara S, Maneval DR Jr, Johnson JA, Kaper JB 1999. A bacteriophage encoding a pathogenicity island, a type IV pilus and a phage receptor in cholera bacteria. Nature 399: 1-4.

Lan R, Reeves PR 1998. Recombination between rRNA operons created most of the ribotype variation observed in the seventh pandemic clone of Vibrio cholerae. Microbiol 144: 1213-1221.

Maiden CJM, Bygraves JA, Feil E, Morelli G, Russell JE, Urwin R, Zhang Q, Zhou J, Zurth K, Caugant DA, Feavers IM, Achtman M, Spratt BG 1998. Multilocus sequence typing: a portable approach to the identification of clones within populations of pathogenic microorganisms. Proc Natl Acad Sci USA 95: 3140-3145.

Pasteur N, Pasteur G, Bonhomme F, Catalan J, Britton-Davidian J 1990. Practical Isozyme Genetics. Chichester: Ellis Horwood, 215 pp.

Pollitzer R 1960. Le Cholera, Organisation Mondiale de la Sante, serie de monographies No.43, Geneve, 1065 pp.

Selander RK, Caugant DA, Ochman H, Mosser JM, Gilmour MN, Whittan TS 1986. Methods of multilocus enzyme electrophoresis for bacterial population genetics and systematics. App Env Microbiol 51: 873-884.

Saha PK, Koley H, Mukhopadhyay AK, Bhattacharya SK, Nair GB, Ramakrishman BS, Krishnan S, Takeda T, Takeda Y 1996. Non toxigenic Vibrio cholerae O1 serotype Inaba Biotype El Tor associated with a cluster of cases of cholera in Southern India. J Clin Microbiol 34: 1114-1117.

Salles CA, Momen H 1991. Identification of Vibrio cholerae by enzyme electrophoresis. Trans $R$ Soc Trop Med Hyg 85: 544-547.

Tibayrenc M, Neubauer K, Barnabe C, Guerrini F, Skarecky D, Ayala FJ 1993. Genetic characterization of six parasitic protozoa: parity between random-primer DNA typing and multilocus enzyme electrophoresis. Proc Natl Acad Sci USA 90: 1335-1339.

Wachsmuth IK, Evins MG, Fields I, Olsvik O, Popovic T, Bopp CA, Wells JG, Carrillo C, Blake Paul A 1993. The molecular epidemiology of cholera in Latin America. J Infect Dis 167: 621-626.

Wachsmuth IK, Blake PA, Olsvik O 1994. Vibrio cholerae and Cholera, MAS press, Washington D.C. 465 pp. 